\title{
Critical segments in the dissemination and transmission of Salmonella species from poultry production in Calabar, Nigeria
}

\author{
Nchawa Yangkam Yhiler ${ }^{1}$, Bassey Enya Bassey ${ }^{1,2, ~ * ~}$ \\ ${ }^{1}$ Department of Medical Laboratory Science, Faculty of Allied Medical Science, University of Calabar, Calabar, Nigeria \\ ${ }^{3}$ World Health Organization, UN HOUSE, Plot 617/618, Central Area District, FCT, Abuja, Nigeria
}

Email address:

yankgam@yahoo.com (N. Y. Yhiler), bassey69@yahoo.com (B. E. Bassey)

\section{To cite this article:}

Nchawa Yangkam Yhiler, Bassey Enya Bassey. Critical Segments in the Dissemination and Transmission of Salmonella Species from Poultry Production in Calabar, Nigeria. Science Journal of Public Health. Vol. 3, No. 2, 2015, pp. 168-174. doi: 10.11648/j.sjph.20150302.13

\begin{abstract}
Salmonella species are ubiquitous enteric bacteria, its ability to survive at different stages of the poultry production and food processing chain has been frequently reported in recent years. The present study was undertaken to investigate the points in the segments involved in the production of poultry in Calabar as vital sources of dissemination and transmission of Salmonella species to humans. A total of 374 samples were collected from three study segments involved in the production of poultry in Calabar, within the period of August 2013 and May 2014. 170 samples were collected from different points in poultry environment which includes (feed from feeders, water from drinkers, litter/faeces from floor, abattoir reins and drag swab from wall); 136 samples were taken from the live birds (cloacal swab, gut, carcass and egg); and 68 samples were derived from poultry handlers (stool specimens and hand wash). The samples were collected aseptically and analysed for the presence of Salmonella species based on the ISO 6579:2002 involving standard bacteriological, biochemical and serologic techniques. The Chi-square, student t-test and simple descriptive statistics were used to analyse the data obtained in this study at $95 \%$ confidence level. Salmonella species were recovered from $221(59.1 \%)$ of the examined samples involved in the production of poultry in Calabar. There was no significant statistical difference in the rate of recovery of Salmonella species from the poultry environmental segment (58.8\%), bird segment (55.1\%) and poultry handlers segment $(67.6 \%)(P=0.230)$, implying that these three segments are equally important in the maintenance, dissemination and transmission of Salmonella species. Salmonella species were recovered from all the study sample points implying that all the study poultry sample points are sources of Salmonella species. However, the highest recovery rate of Salmonella species was observed in the stool sample points of poultry handlers $(91.2 \%)$ and poultry gut sample points $(79.4 \%)$ which were significantly different from the rest of the poultry sample points $(P=0.021)$, implying that these two sample points are the major sources of Salmonella species and are critical in the dissemination and transmission of Salmonella species.
\end{abstract}

Keywords: Salmonella Spp, Poultry, Production Segment, Dissemination/Transmission

\section{Introduction}

Poultry industry possesses an enormous influence in terms of providing the consumer with good quality protein worldwide. The growth of poultry industry in Nigeria is on a dramatic rise and more than $25 \%$ of the total meat production in Nigeria comes from poultry [1]. The poultry industry faces significant challenges in terms of animal health and reduced productivity [2]. The major challenges in poultry production systems worldwide have been frequently attributed to Salmonella infection. Salmonella organisms have been identified as the major cause of mortality; it is responsible for more than $40 \%$ of the death of birds [3] poor chick and egg production [4]

There are other several segments involved in poultry production system and Salmonella organisms are not able to establish in all these segments [5].

Other studies have documented the ability of these organisms to survive in animal feeds for more than two years and in the faeces of infected birds for nearly two weeks [6]. Salmonella organisms can be maintained in the intestines and gonads of infected birds throughout their life time and the 
manifestations may be either overt or asymptomatic and can also transfer the infection to the subsequent generation of birds $[1,6]$.

These factors therefore render the segments involved in the production of poultry a vulnerable platform for the introduction, establishment and dissemination of the Salmonella species. This may result in the infection and reinfection of the birds, as well predisposing the consuming population at risk of developing the disease [7]. Furthermore, the poultry production systems are designed to ensure the massive production of birds usually in confinement. This design is necessary to meet the high protein demand, it also promote the introduction and establishment of the Salmonella organisms and hence transmission to the consuming population $[8,9]$.

Poultry handlers involved in the production of poultry come into direct or indirect contact with the birds or its carcasses. Hence, they also play an important role in the introduction of Salmonella to the birds and in the transmission of the infection to the general public. This ranks the Salmonella organisms a high priority hazard both in terms of public health and animal health [10].

In spite of the frequent incrimination of poultry as the major reservoir of Salmonella species, there is relatively paucity of data with respect to the level of distribution of Salmonella species in the various segments involved in the production of poultry. Also, the Hazard Analysis Critical Control Point (HACCP) programs that have been implemented in the western world have proven unsuccessful in the developing countries. In order therefore to implement effective prevention and control strategies, we evaluated the epidemiology of Salmonella species to understand the vulnerability of the various segments involved in the production of poultry in the dissemination and transmission of Salmonella infection.

\section{Materials and Methods}

\subsection{Study Area}

This study was conducted within the period of August 2013 to May 2014 in Calabar metropolis, Cross River State, Nigeria (Latitude $4.95^{\circ}$ North and Longitude $8.32^{\circ}$ East) with an elevation of 99 metres above the sea level. It has a population of about 461,796 inhabitants [11]. The commercial poultry production system in Calabar has rapidly developed over the years in terms of size and spread.

\subsection{Sample Collection}

A total of 374 samples were collected from 34 randomly selected poultry farms within the Calabar, out of the collected samples 170 samples came from 5 different environmental points i.e. (poultry feed from feeders (E1), water from drinkers (E2), litter/faeces from floor (E3), water from carcass reins (E4) and drag swab from wall (E5) 34 samples each) 136 samples were collected from birds segment which included (cloacal swab (S1), gut samples (S2), ready-to distribute samples (S3) and egg samples (S4 34 samples each) in addition to 68 humans samples consisting of stool specimens and poultry handlers hand wash 34 samples each were obtained from 2 poultry handlers segment points.

Samples were collected aseptically in sterile polythene bags and sterile universal bottles were applicable and were kept in a cold box containing ice packs prior to transfer to the laboratory for bacteriological analysis within 12 hours.

\subsection{Isolation of Salmonella Species}

The isolation and identification of Salmonella species from the segments in the commercial production of poultry was performed in according to ISO 6579:2002. The reagents were obtained from HARDY Diagnostics, 1430 West McCoy Lane, Santa Maria, CA 93455, USA.

In the non-selective pre-enrichment stage, a dilution of 1:10 of each sample was made by weighing out $25 \mathrm{~g}$ of the solid sample by means of a digital weighing scale (or measuring out $25 \mathrm{ml}$ of the liquid sample by means of a sterile measuring cylinder) with $225 \mathrm{ml}$ of $10 \%$ modified Buffered Peptone Water (BPW) into a sterile conical flask and shaken well to mix. This was then allowed in a dark corner over night at ambient temperature.

By means of a sterile pipette, $1 \mathrm{ml}$ and $0.1 \mathrm{ml}$ of the nonselective enrichment was then inoculated into $9 \mathrm{ml}$ of MullerKauffmann Tetrathionate-novobiocin (MKTTn) and Modified Semisolid Rapapport-Vassiliadis (MSRV) selective enrichments respectively. These were respectively incubated at $37^{\circ} \mathrm{C}$ and $42^{\circ} \mathrm{C}$ in separate incubators for 18 to $24 \mathrm{~h}$.

After incubation, a loop full from each of the selective enrichments was streaked onto both Brilliant Green Agar (BGA) and Xylose Lysine Desoxycholate Agar (XLDA) selective plates in order to obtain distinct Salmonella-like colonies. On BGA, typical Salmonella-like colonies appear as 1-2 mm pink colonies which convert the agar from green to red whereas on XLDA, they appear as pink colonies with or without the presence of black centres (indicating the production of $\mathrm{H}_{2} \mathrm{~S}$ ).

The typical Salmonella-like colonies on BGA and XLDA were then picked by means of a sterile wire needle. The needle was used to make a smear on a microscopic slide for gram staining and then used to stab and streak on preprepared Triple Sugar Iron Agar (TSIA) and Christensen agar (CA) slants. Those Salmonella-like colonies that showed Gram-negative small rods by microscopy, produced alkaline slope/acid butt with or without the production of $\mathrm{H}_{2} \mathrm{~S}$ and gas, on TSIA slant and urease negative on Christensen agar slant were considered suggestive of Salmonella. They were then sub-cultured on nutrient agar slants overlaid with sterile paraffin oil and kept in a cool dark corner prior to further biochemical reactions [12].

\subsection{Confirmation of Salmonella Species}

Confirmation of Salmonella species were carried out based on the standard biochemical techniques in order to identify the isolates which belong to the genus Salmonella It involved 
the use of Lycine Decarboxilation (LCD) test, $\beta$ galactosidase test, Acetone production test and Indole production test.

Serotyping of obtained Salmonella isolates was further supplemented by means of the commercially available polyvalent Salmonella antisera kit (Denka Seiken Co. Ltd. Tokyo, Japan) specific for all group and type-factor Salmonella antigens. A loop full from Salmonella isolates that satisfy all the confirmation procedures was then emulsified with one drop of normal saline $(0.85 \% \mathrm{NaCl})$ on a microscopic glass slide. The preparation was gently stirred and observed for auto-agglutination. If there was no selfagglutination, a drop of the polyvalent antisera was added and gently agitated by rocking back and forth for about three minutes and observed for agglutination. Those that showed agglutination were considered to belong to the genus Salmonella [12].

\subsection{Statistical Analysis}

The data obtained in this study were analysed by means of the Predictive Analytical Software (PASW) 18.0. The simple descriptive statistics was used to analyse the prevalence rate of Salmonella species in the samples obtained from the production of poultry. The Chi-square parameter and the student t-test were used to determine the level of significance in the rate of recovery of the Salmonella species .P-values of less than 0.05 were considered statistically significant.

\section{Result}

\subsection{Prevalence of Salmonella Species}

Out of the 374 specimens analysed from the three segments in the production of poultry in Calabar, $221(59.1 \%)$ were positive for Salmonella species. The samples from the poultry environmental segment recorded a prevalence rate of $58.8 \%$, the samples from the poultry bird segment, $55.1 \%$ and from the poultry personnel segments $67.6 \%$. However, the difference in the rate of recovery of Salmonella species among the three poultry segments in the production of poultry in Calabar was not statistically significant $\left(\chi^{2}=2.939\right.$, $d f=2, P$-value $=0.230)$.

Among the five poultry environmental segment sample points, the highest rate of recovery of Salmonella species occurred in E3 (litter/faeces from floor) (14.1\%) and the least from E5 (drag swab from wall) $(8.2 \%)$ but there was no significant statistical difference in the rate of recovery of Salmonella species from the points of the poultry environmental segment $\left(\chi^{2}=8.986, d f=4, P\right.$-value $\left.=0.061\right)$. Among the four poultry bird segment sample points, the sample point that revealed the highest rate of recovery came from S2 (gut samples) (19.9\%) and the least from S4 (egg samples) $(5.9 \%)$. The difference in the rate of recovery of Salmonella species from the points of the poultry bird segment was statistical significant $\left(\chi^{2}=24.444, d f=3, P\right.$ value $=0.000)$. Among the two poultry personnel segments, the highest $(45.6 \%)$ and the least $(22.1 \%)$ rate of recovery of Salmonella species came respectively from P1 (poultry personnel stool samples) and P2 (poultry personnel hand wash samples) respectively. There was also a statistical significant difference in the rate of recovery of Salmonella species from the sample points of the poultry personnel segment $\left(\chi^{2}=17.202, d f=1, P\right.$-value $\left.=0.000\right)$.

When considering the individual sample points from all the three poultry production segments in Calabar, P1 (poultry personnel stool samples) and S2 (poultry bird gut samples) respectively had the highest rate of recovery of Salmonella species of $91.2 \%$ and $79.4 \%$, whereas S4 (poultry bird egg samples) had the least rate of recovery of Salmonella species of $23.5 \%$ (Table 2). However, the difference in the rate of recovery of Salmonella species from the individual poultry sample points of the segments involved in the production of poultry was statistically significant $\left(\chi^{2}=50.482, d f=10, P\right.$ value $=0.000$ ).

Table 1. Recovery of Salmonella species from the various segments in the production of poultry.

\begin{tabular}{|c|c|c|c|c|c|c|c|c|c|c|c|c|c|c|}
\hline \multicolumn{15}{|c|}{ Sources of Salmonella samples $(n=374)$} \\
\hline \multirow{2}{*}{$\begin{array}{l}\text { Poultry Segments } \\
\text { Poultry Sample Points }\end{array}$} & \multicolumn{6}{|c|}{ Environment $(\mathrm{n}=170) P=0.061$} & \multicolumn{5}{|c|}{ Bird $(n=136) P=0.000$} & \multicolumn{3}{|c|}{$\begin{array}{l}\text { poultry handlers }(n=68) P= \\
0.000\end{array}$} \\
\hline & E1 & E2 & E3 & E4 & E5 & Tot. & $\mathrm{S} 1$ & $\mathrm{~S} 2$ & S3 & S4 & Tot. & P1 & P2 & Tot. \\
\hline No. Positive & 17 & 22 & 24 & 23 & 14 & 100 & 19 & 27 & 21 & 8 & 75 & 31 & 15 & 46 \\
\hline$\%$. Positive & $10.0_{\mathrm{a}}$ & $12.9 \mathrm{a}$ & $14.1_{\mathrm{a}}$ & $13.5_{\mathrm{a}}$ & $8.2_{\mathrm{a}}$ & $58.8_{\mathrm{b}}$ & $14.0_{\mathrm{c}}$ & $19.9_{\mathrm{d}}$ & $15.4_{\mathrm{e}}$ & $5.9_{\mathrm{f}}$ & $55.1_{\mathrm{b}}$ & $45.6_{\mathrm{g}}$ & $22.1_{\mathrm{h}}$ & $67.6_{b}$ \\
\hline
\end{tabular}

Subscripts a-h: the same letter subscript indicates no statistical significant difference while different letter subscript indicates significant statistical difference.

a: no statistical significant difference among the environmental sample points (E1 - E5)

b: no statistical significant difference among the three poultry segments

c-f: significant statistical difference among the bird sample points (S1 - S4)

$\mathrm{g}-\mathrm{h}$ : significant statistical difference among the personnel sample points (P1 and P2)

E1: poultry feed from feeders

E2: water from drinkers

E3: litter/faeces from floor

E4: carcass reins water

E5: drag swab from wall

S2: gut samples

S3: ready-to-distribute samples

S4: egg samples

P1: personnel faecal samples

$\mathrm{P} 2$ : personnel hand wash samples 
Table 2. Distribution of Salmonella species by sample points in the production of poultry.

\begin{tabular}{llll}
\hline Sample Points & Number collected & Number positive & Percentage positive \\
\hline E1 & 34 & 17 & 50.0 \\
E2 & 34 & 22 & 64.7 \\
E3 & 34 & 24 & 70.6 \\
E4 & 34 & 23 & 67.6 \\
E5 & 34 & 14 & 41.2 \\
S1 & 34 & 19 & 55.9 \\
S2 & 34 & 27 & 79.4 \\
S3 & 34 & 21 & 61.8 \\
S4 & 34 & 8 & 23.5 \\
P1† & 34 & 31 & 91.2 \\
P2 & 34 & 15 & 44.1 \\
TOTAL & 374 & 221 & 59.1 \\
\hline
\end{tabular}

*† indicate critical poultry sample points (major source of Salmonella species) from the segments in the production of poultry in Calabar.

E1: poultry feed from feeders

E2: water from drinkers

E3: litter/faeces from floor

E4: carcass reins water

E5: drag swab from wall

S1: cloacal swab

S2: gut samples

S3: ready-to-distribute samples

S4: egg samples

P1: personnel faecal samples

P2: personnel hand washing

\section{Discussion}

Salmonella species have been established as a significant problematic zoonosis worldwide and they are responsible for the significant challenges encountered in the food production systems of which the poultry production system is a major concern [12]. In this study, the rate of recovery of Salmonella species in the poultry production system within Calabar Metropolis was revealed to be $59.1 \%$. This recovery rate is considerably high and hence suggests that the poultry production systems in Calabar are important reservoirs of Salmonella species. This poses a serious threat both to the poultry birds themselves and most importantly to the consumer population. Several studies from different parts of the world have revealed varying recovery rates of the contamination of poultry samples by Salmonella species: a prevalence rate of $70.5 \%$ was reported in Brazil [13], 63.6\% in Ethiopia [14], 53\% in Vietnam [15], 35\% in Spain [16], $26.6 \%$ in Bangladesh [17], $17 \%$ in USA [18], $10.1 \%$ in Georgia [19], 5\% by [20] and $1 \%$ in Jamaica [21]. Such varying prevalence rates could be attributed to the differences in the geographical location as well as the standards of hygiene and sanitation practices observed by these regions. However, in 2009 in the Adamawa state of Nigeria, a prevalence rate of $40.8 \%$ was reported [3], while this current study carried out within the Calabar metropolis of Nigeria, in 2013-2014 recorded a prevalence rate of 59.1\%. This suggests an increasing trend in the rate of recovery of Salmonella species from the poultry production system in Nigeria and that the hygiene/sanitation practices are poor. It also suggests that the implementation of control strategies if any is unsuccessful. The rate of recovery of Salmonella species from the three segments in the production of poultry in Calabar showed no significant statistical difference $(P=$ 0.230), implying that Salmonella species are well distributed in the three segments of poultry production in Calabar and hence making them significant sources.

There are several points involved in the production of poultry where the Salmonella organisms are capable of colonizing. Once a stage involved in the production of poultry becomes colonized, it puts the poultry at risk of death thereby leading to losses and also renders the poultry unsafe for human consumption. Among the poultry environmental segment sample points (E1, E2, E3, E4 and E5), there was no statistical significant difference $(P=0.061)$ in the rate of recovery of Salmonella species. Therefore, the environmental sample points are all good sources of Salmonella species.

This current study demonstrated a $50.0 \%$ rate of recovery of Salmonella species from the poultry feed from feeder (E1) sample points in the production of poultry. Several studies have frequently implicated poultry feeds as an important source of Salmonella species [22]. Other researchers demonstrated a rate of $1.4 \%$ of Salmonella species from poultry feeds [23] and Liljebjelke recorded 3.6\% [19] which is not in agreement with the findings in this study. However, the work of Maqsood in Pakistan demonstrated 65.8\% [24] and in Zaria, Nigeria researchers recorded $63.8 \%$ rate of Salmonella contamination of poultry feeds [4] which corroborates the findings recorded in this study. Such high recovery rates are an indication that there is inappropriate or no monitoring of feed in the poultry production chain and that the handling of feed in the poultry production chain is poor. This poses serious threat to the health of the poultry birds and consequence, the consumer population.

In the present study a high rate of recovery of Salmonella species $(64.7 \%)$ from the water from drinker sample points 
(E2) were recorded. In Georgia a low recovery rate of $1.8 \%$ Salmonella species from poultry drinking water [19] was recorded as opposed to the relatively high prevalence rate $(55.3 \%)$ demonstrated in Nigeria [4]. This suggests that the water reserves in the poultry production systems in Calabar are significantly contaminated probably due to the contamination of tap heads and/or the containers used to fetch water. It also suggests that the poultry drinking water are not appropriately treated or not treated at all and that the hygiene and sanitation standards within the poultry production chain are poor. Inasmuch as the water reserves are exclusively for the poultry birds, such poultry drinking water is an important source of Salmonella species leading to the infection of the birds and hence the consumer population.

In USA, a prevalence rate of $29 \%$ was reported from poultry litter [25], Liljebjelke et al., recorded $21.8 \%$ in Georgia [19] and 2\% in Jamaica [21]. However, this study recorded high $(70.6 \%)$ rate of recovery of Salmonella isolates from the poultry litter/faeces sample points (E3) in Calabar. This could be due to the frequent contamination of the floor with infected bird faeces. In spite of the regular changing of litter from floor, the litter or floor in the production of poultry in Calabar are hardly treated. This promotes conditions that favour the survival of the Salmonella species. This puts the entire flock at risk of infection which can lead to the massive death of birds [4].

The rate of recovery of Salmonella species from the poultry carcass reins sample points (E4) in the production of poultry was recorded to be $67.6 \%$ in this study. A study carried out by Baoet al., recorded a rate of recovery of $48 \%$ [26] which closely agrees with the result of this study. However, the high rate of recovery of Salmonella species from poultry carcass reins may be as a result of the common practice of using an over diluted carcass reins solution and using the same water for a large number of carcass hence reducing its potency of destroying microorganisms. This is very dangerous as entire slaughter line can become contaminated rendering the carcasses unsafe for human consumption.

The recovery rate of Salmonella species from poultry house drag swab sample points (E5) were $41.2 \%$ our results were in agreement with other studies[19, 27] which reported $39.3 \%$ and $40.9 \%$ rate of recovery of Salmonella species from poultry house drag swabs. Contaminated dust from the walls of the poultry house or any other poultry equipment is an important source of contamination and recontamination of any segment in the poultry production system even after disinfection. This therefore could account for the high prevalence rate of Salmonella species from the production of poultry in Calabar.

In this study, cloacal swab sample point (S1) recorded a prevalence rate of $55.9 \%$. This is relatively high compared to the results of other researchers [28, 29, 17] who demonstrated prevalence rates of $4 \% 19 \%$ and $26.3 \%$ respectively from poultry cloacal swabs. The relatively high prevalence rate of Salmonella from cloacal swabs as recorded by this study suggests that high number the poultry birds in
Calabar are infected with the Salmonella species.

The recovery rate of Salmonella species from the gut sample points (S2) of the poultry bird segment in this study was reported to be $79.4 \%$. This result closely corroborates the $31.6 \%, 60 \%$ and $93.5 \%$ respectively $[30,17,21]$. Such high prevalence rates suggest that the birds themselves harbour the Salmonella species in their gut to considerable levels and as a consequence can be attributed to the death of birds, reduced egg and chick productivity from the stand point of animal health and also economically. This can also be implicated to the contamination of the poultry environment via faeces and consequently making them significant reservoirs in the transmission of the infection to the other birds in the flock as well as humans and other animals [10].

The rate of recovery of Salmonella species from ready to distribute poultry meat sample points (S3) as recorded by this study was $61.8 \%$. Several studies carried out in both the developed and the developing worlds have demonstrated the prevalence rate of chicken carcass contaminated with Salmonella to range from $0 \%$ to $40 \%$ [31]. However, higher prevalence rates of $48.8 \%$ and $45.6 \%$ have been reported in Karachi and Dubai from poultry slaughter carcass [32, 33]. Nonetheless these high contamination rates are an indication that chicken meat remains an important source of Salmonella infection to the consumer population. The result of this study suggests that the poor hygienic and sanitation practices exercised by the poultry abattoirs are important in the contamination of chicken meats destined for human consumption.

In this study, the prevalence rate of Salmonella species from the poultry bird segment egg (S4) sample points was $23.5 \%$. This contradicted the works of EFSA, [21, 37] and Suresh [34] who recorded relatively very low prevalence rates of $0.34 \%, 1 \%$ and $1.8 \%$ of Salmonella contaminated eggs respectively. Nevertheless, the work carried out in Plateau, Nigeria recorded a prevalence rate of $32.5 \%$ from retailed eggs [35]. The high rate of Salmonella contaminated eggs could be attributed to the high level of environmental contamination as well as the poor hygiene and poor sanitatary practices observed by the egg handlers. Moreover, Salmonella Typhimurium and Salmonella Enteritidis are the serovars that have been most frequently incriminated to be capable of penetrating egg shells leading to the contamination of the egg content. They are responsible for the contamination of eggs even before they are laid during transovarian transmission [36]. The consumption of such raw or undercooked eggs is a serious hazard to the consumer population.

There was a significant difference in the rate of recovery of Salmonella species from the poultry bird segment sample points (S1, S2 S3 and S4) $(P=0.000)$. Therefore, the rate of recovery of Salmonella species from the poultry bird gut sample points (S2) was significantly high, thereby implicating it as the major source of Salmonella species among the samples of the poultry bird segment.

Poultry handlers have been recognized as the most important epidemiologic factor in the introduction and 
dissemination of Salmonella species within the poultry production system [38]. In this current study, the rate of recovery of Salmonella species from poultry handlers stool and Poultry handlers hand wash sample points was $91.2 \%$ and $44.1 \%$ respectively. This result reveals that the greater majority of the poultry handlers have a significant level of intestinal carriage of the Salmonella species hence making them potential factors in the contamination of all the other poultry segments they come in contact with. The result of this study also extrapolates that the sanitary and hygienic standards of the poultry handlers are very poor. Since the poultry handlers are almost always in contact with all the segments involved in the production of poultry, they play a significant role in the introduction and dissemination of the Salmonella organisms in the poultry production system as well as transmission to other humans by account of their contact with other human outside the poultry setting.

Among the poultry handlers segment sample points (P1 and $\mathrm{P} 2)$, there was a significant difference in the rate of recovery of Salmonella species $(P=0.000)$. Since the poultry handlers stool sample points $(\mathrm{P} 1)$ had the highest rate of recovery of Salmonella species, it also serve as a major source of Salmonella species among the poultry handlers segment sample points.

The rate of recovery of Salmonella species from the individual sample points was significantly different $(P=$ $0.000)$. Therefore, P1 (91.2\%) and S2 (79.4\%) which had the highest rate of Salmonella species from the individual sample points serve as the major sources of Salmonella species that are critically important in the dissemination and transmission of the Salmonella species to humans and other animals.

\section{Conclusion}

The results of this study have demonstrated the recovery of significant levels of Salmonella species from the poultry segments involved in the production of poultry in Calabar. Hence, all the segments involved in the production of poultry in Calabar are important sources of Salmonella to both the birds themselves and the consumer population. However, the birds and the Poultry handlers are critical sources in the dissemination and transmission of Salmonella species to humans.

The control of Salmonella from all the segments involved in the production of poultry is vital in the management and control of Salmonella species within the poultry setting. Hence, prompt identification of Salmonella species from the segments involved in the production of poultry is vital in preventing the introduction of the Salmonella species in the food chain and hence preventing the transmission of the infection to the consumers.

There is therefore the urgent need for the institution of surveillance Salmonella systems for poultry farms and abattoirs in order to regulate the extent of avian and human salmonellosis. In addition, the poultry handlers should be properly educated on the demerits of insanitary and unhygienic habits and the benefits of strict adherence to sanitation and hygiene protocols with the ultimate goal of minimising or eliminating the hazard of Salmonella contaminations.

\section{References}

[1] Mbuko, I. J., Raji, M. A., Ameh, J., Saidu, L., Musa, W. I. \& Abdul, P. A.. Prevalence and seasonality of fowl typhoid disease in Zaria-Kaduna State, Nigeria. Journal of Bacteriology Research, 2009; 1(1): 001-005

[2] Kanashiro A. M. I., Stoppa, G. F. Z., Cardoso, A. L. S. P., Tessari, E. N. C. \& Castro, A. G. M. Serovars of Salmonella spp. isolated from broiler chickens and commercial breeders in diverse regions in Brazil from July 1997 to December 2004. Rev. Bras. Cienc.Avic. 2005; 7:195-198.

[3] Garba, A., Bolajoko, B. M.,.Barde, A. Ahmed, I., Sa'adatu, I. Agang, A. S., Abdullahi, H. A., Bakari, U. I. J., Uraki, A. T., Abdurrahman, A.\& Goji, J. N.. The threat of Salmonellasis to commercial poultry production in Adamawa state, Nigeria.Sokoto Journal of Veterinary Sciences, 2010; 8(1): $50-52$

[4] Musa, I. W., Mansur, M. S., Sa'idu, L., Mohammed, B., Kaltungo, B. Y., Lawan, M. K., Talba, A. M.. Isolation and Antibiogram of Salmonella Species from Water and Poultry Feed In Selected Commercial Farms In Zaria, Nigeria. Time Journals of Agriculture and Veterinary Sciences, 2014; 2(2): 75-80.

[5] Cox, J. M. \& Pavic, A. (2010). Advances in enteropathogen control in poultry production. Journal of Applied Microbiology, 108: 745-755.

[6] Bersot, L. S. Salmonella Brasil: Sua importância no abatede aves. In: V Simpósio de sanidadeavícola da UFSM. Anais, Santa Maria, UFSM, 2006; 90-94.

[7] Tessari, E. N. C., Cardoso, A. L. S. P., Castro, A. G. M.. Prevalência de Salmonella Enteritidis em carcaças de frango industrialmente processadas. Revista Higiene Alimentar, 2003; 17(107): 52-55.

[8] Velge, P. C. \& Barrow P. Emergence of Salmonella epidemics: the problem related to Salmonella enteric serotype Enteriditis and multiple antibiotic resistances in other major serotypes. Veterinary Research, 2005; 36: 276-288

[9] Pui, C. F., Wong, W. C., Chai, L. C., Nillian, E., Ghazali, F. M., Cheah, Y. K., Nakaguchi, Y., Nishibuchi, M. \&Radu, S.). Simultaneous detection of Salmonella spp., SalmonellaTyphi and Salmonella Typhimurium in sliced fruits using multiplex PCR. Food Control, 2011b; 22: 337-342.

[10] Okonko, I. O., Nkang, A. O., Fajobi, E. A., Mejeha, O. K., Udeze, A. O., Motayo, B. O., Ogun, A. A., Ogunnusi, T. A. \& Babalola, T. A. Incidence of multi-drug resistant (MDR) organisms in some poultry feeds sold in Calabar metropolis, Nigeria. EJEAFChe, 2010; 9 (3): 514-532.

[11] National Population Commission. Federal Republic of Nigeria Official Gazette 2007; 4(94), 233

[12] OIE Terrestrial Manual 2008. World organisation for animal health manual of diagnostic tests and vaccines for terrestrial animals (mammals, birds and bees), Sixth Edition, Volume 2, 2008. 
[13] Kanashiro A. M. I., Stoppa, G. F. Z., Cardoso, A. L. S. P., Tessari, E. N. C. \& Castro, A. G. M.. Serovars of Salmonella spp. isolated from broiler chickens and commercial breeders in diverse regions in Brazil from July 1997 to December 2004. Rev. Bras. Cienc.Avic. 2005; 7:195-198.

[14] Molla, B. D., Alemayehu, L. \& Salah W.. Sources and distribution of Salmonella serotypes isolated from food animals, slaughterhouse Poultry handlers and retail meat products in Ethiopia. Ethiopian Journal of Health Development, 2003; 17(1): 63-70

[15] Thi Thu Hao Van, George Moutafis, Taghrid Istivan, Linh Thuoc Tran, and Peter J. Coloe. Detection of Salmonella spp. in Retail Raw Food Samples from Vietnam and Characterization of Their Antibiotic Resistance. Applied Environmental Microbiology, 2007; 73 (21): 6885-6890

[16] Dominguez, C., Gomez and Zumalacarregui .Prevalence of Salmonella and Campylobacter in retail outlet in Spain.International Journal of Food Microbiology, 2002; 72(1): 165-168.

[17] Akond, M. A., Shirin, M., Alam S., Hassan, S. M. R., Rahman, M. and Hoq M.Frequency of drug resistant Salmonella spp. isolated from poultry samples in Bangladesh. Stamford Journal of Microbiology, 2012; 2:1

[18] C.M. Logue, J.S. Sherwood, P.A. Olah, L.M. Elijah and M.R. Dockter). The incidence of Antimicrobial-Resistant Salmonella spp. on Freshly Processed Poultry from US Midwestern Processing Plants. Journal of Applied Microbiology, 2003; 94:16-24.

[19] Liljebjelke, K. A., Hofacre, C. L., Liu, T., White, D. G., Ayers, S. S. Y. \& Maurer, J. J..Vertical and Horizontal Transmission of Salmonella within Integrated Broiler Production System. Foodborne Pathogens and Disease, 2005; 2(1).

[20] Muhammad, M., Lawal, U. M., Abdul-Ganiyu, A., Aliyu, U. M., Samuel, A. \& Lisa, B. Prevalence of Salmonella associated with chick mortality at hatching and their susceptibility to antimicrobial agents. Veterinary Microbiology, 2010; 140: $131-135$.

[21] Curtello, S., Justiz, A. A., Vaillant, H., Asemota, P. E. A. \& Monica, P. S. Prevalence of Salmonella Organisms in Poultry and Poultry Environments in Jamaica. British Microbiology Research Journal, 2013; 3(4): 461-469.

[22] Jones, F. T. \& Richardson, K. E.. Salmonella in commercially manufactured feeds.Poultry Sciences, 2004; 83: 384-391.

[23] Veldman, A., Vahl, H. A., Borggreve, G. J. \& Fuller, D. C. A survey of the incidence of Salmonella species and Enterobacteriaceae in poultry feeds and feed components. Veterinary Record, 1995; 136(7):169-72.

[24] Maqsood, A. Salmonella prevalence in the poultry feed industry in Pakistan Swedish University of agricultural sciences faculty of veterinary medicine and animal science; 2012 http://epsilon.slu.se

[25] Volkova, V. V., Bailey, R. H. \& Wills, R. W. Salmonella in Broiler Litter and Properties of Soil at Farm Location. PLoS 2009; 4(7):

[26] Bao, N., Fries, R., Zessin, K. H., Kyule, M. N., Pinthong R. \& Baumann M. P. O. (2006).Salmonella and Campylobacter in Broiler Carcasses In Vietnam. Proceedings of the 11th International Symposium on Veterinary Epidemiology and
Economics, Available at www.sciquest.org.nz

[27] Mueller-Doblies, D., Sayers, A. R., Carrique-Mas, J. J. \& Davies, R. H. Comparison of sampling methods to detect Salmonella infection of turkey flocks, Journal of Applied Microbiology, 2009; 107: 635-645

[28] García, C., Soriano, J. M., Benítez, V.\& Catalá-Gregori, P. Assessment of Salmonella spp. in feces, cloacal swabs, and eggs (egg shell and content separately) from a laying hen farm.Journal of Poultry Science, 2011; 90(7):1581-5.

[29] Al-Abadi, I. K. M. \& Al-Mayah, A. A. S. Isolation and identification of Salmonella spp. from chicken and chicken environment in Basrah province. Journal of poultry Science, 2006; 6(2): 88-99.

[30] Begum, K., Reza, T. A., Hague, M., Hossain, A., Hassan, F. M K., Hassan, S. N., Akhter, N., Ahmed, A. \& Barua, U. Isolation, Identification and antibiotic resistance pattern of Salmonella spp. from chicken eggs, intestines and environmental samples. Bangladesh Pharmaceutical Journal, 2010; 13: 23-27.

[31] J.S Bailey, N.J Stern, P Fedorka-Cray, S.E Craven, N.A Cox, D.E Cosby, S Ladely, M.T Musgrove Sources and movement of Salmonella through integrated poultry operations: a multistate epidemiological investigation J. Food Prot., 2001; 64 (11) 1690-1697.

[32] Shah, A. H. \& Korejo, N. A. Antimicrobial Resistance Profile of Salmonella Serovars Isolated from Chicken Meat. Journal of Veterinary and Animal Science., 2012; 2: 40-46

[33] Khan, M., Ali, P., Suryanarayan M., Musthaq A., Reshma, B., Vaswani S. \& Mohammed F. Antimicrobial susceptibility of Salmonella isolates from chicken meat samples in Dubai, United Arab Emirates. International Journal of Food, Nutrition and Public Health, 2010; 3(2).

[34] Suresh, T.; Hatha, A. A. M.; Screenivasa, D. Prevalence and antimicrobial resistance of Salmonella Enteritidis and other salmonella in the eggs and eggstoring trays from retails markets of Coimbatore, south India. Food Microbiology, 2006; 23(3) 294-299.

[35] Mai, H. M., Zahraddeen, D., Qadeers, M. A, Bawa, I. A. \& Echeonwu, I. E. .Investigation of Some Species of Salmonella in Table Eggs sold at Different Markets in Jos South, Plateau State, Nigeria. Global Advanced Research Journal of Microbiology, 2013; 2(11): 234-238.

[36] Angulo, F. J., Nargund, V. N. \& Chiller, T. C. Evidence of an association between use of antimicrobial agents in food animals and anti-microbial resistance among bacteria isolated from humans and the human health consequences of such resistance. Journal of Veterinary Medicine. B. Infectious Diseases and Veterinary Public Health, 2004; 51:374-379.

[37] European Food Safety Agency, EFSA. Opinion of the scientific panel on biological hazards on a request from the commission related to the use of antimicrobials for the control of Salmonella in poultry. The European Food Safety Agency Journal, 2004; 115: 1-76.

[38] Elena Carrasco, Morales-Rueda A, García-Gimeno, R. M. Cross-contamination and recontamination by Salmonella in foods: A review. Food Research International, 2012; 45(2), $545-556$ 